\title{
Does living in a poor neighbourhood result in network poverty? A study on local networks, locality-based relationships and neighbourhood settings
}

\author{
Gwen van Eijk
}

Received: 1 November 2009/Accepted: 1 May 2010/Published online: 12 October 2010

(C) The Author(s) 2010. This article is published with open access at Springerlink.com

\begin{abstract}
This paper examines whether and how living in a poor neighbourhood results in "network poverty". Through a detailed analysis of the formation of personal networks of people living in a poor neighbourhood and those living in an affluent neighbourhood in Rotterdam, I examine the role of the neighbourhood in the formation of personal networks. I address three issues. First, whether resource-poor people who live in a poor neighbourhood form relationships with fellow-residents to compensate for their otherwise small network. I find that they do not and that their small network is primarily caused by non-participation in settings such as study, work, leisure and associations. Second, I distinguish locally maintained relationships that have originated in other settings from locality-based relationships that originated in the neighbourhood. The study shows that high network localness is more a matter of maintaining relationships in the neighbourhood than forming many new locality-based relationships with fellow-residents. Third, I examine how the neighbourhood facilitates relationship formation and conclude that this happens not in "the neighbourhood" but in neighbourhood settings, which attract a particular segment of a neighbourhood population. I conclude that the problem of network poverty is not in the first place spatial but rather lies in lack of participation in certain settings. Furthermore, social mixing policies can only be successful if they are accompanied by initiatives to draw a mixed population to neighbourhood settings and facilitate routine encounters between resource-rich and resource-poor people.
\end{abstract}

Keywords Isolation · Personal networks · Poor neighbourhood · Poverty ·

Social capital $\cdot$ Spatial segregation

\section{Introduction}

In a symposium on the "ghetto" in City \& Community, Herbert Gans (2008, p. 356) argues that "researchers have not made the case that residential neighbourhoods, including

G. van Eijk ( $₫)$

Department of Sociology and Anthropology, Amsterdam Institute for Social Science Research, University of Amsterdam, Oudezijds Achterburgwal 185, 1012 DK Amsterdam, The Netherlands e-mail: g.vaneijk@uva.nl 
ghettos, have effects that can be attributed to the neighbourhood per se. (...) The ghetto itself does not often impoverish people.' In other words, studies may have shown that certain "effects" are (statistically) associated with living in a poor neighbourhood (see e.g. Ellen and Turner 1997; Sampson et al. 2002; Small 2007), but few studies have convincingly shown how this would work. In this paper, I examine how the neighbourhood plays a role in network formation for both resource-poor and resource-rich people. The paper builds on observations made in other studies that the neighbourhood may be of importance but in different ways for different categories of people (see e.g. Blokland 2003; Pinkster 2008). Whether the neighbourhood composition affects personal networks, and whether living in a poor neighbourhood causes network poverty, is not only based on whether people live in a certain kind of neighbourhood but also on what they do in their neighbourhood (Blokland 2003). It is not self-evident that people form networks in their neighbourhood and the extent to which they do, and how they do so, varies among people. Based on a detailed empirical study of the networks of residents of a poor neighbourhood and residents of an affluent neighbourhood in Rotterdam, I argue that the role of the neighbourhood in the formation of geographically concentrated networks is not imperative, because such networks are not necessarily formed in the neighbourhood. Furthermore, I argue that in "neighbourhood effects" studies it is often overlooked that people encounter and engage with fellow-residents not in "the neighbourhood" but in settings located in the neighbourhood such as schools, community centres, playgrounds and one's "micro-neighbourhood" of adjacent and nearby dwellings. Lastly, I go into the question of what these refinements of how "neighbourhood matters" mean for the policy of social mixing.

Up to now, I have talked about "the neighbourhood" without specifying what I mean by it. There have been many attempts to define the neighbourhood (e.g. Galster 2001; Kearns and Parkinson 2001) and what seems to be agreed upon is that the neighbourhood is a multifaceted concept. So instead of asking what it is exactly, it may be more fruitful to think about what kind of analytical work the concept of the neighbourhood does in relation to a specific research question. Considering my interest in the formation of personal relationships and networks, we can unravel what the neighbourhood is in terms of network formation. For now, the neighbourhood is a geographical space that people share to live. The scale of this space varies along with people's everyday routines-for some their street is their neighbourhood, for others it is the entire district.

The paper is structured as follows. In the next section, I discuss the theoretical underpinnings of the relation between living in a poor neighbourhood and network poverty. I tease out various aspects of networks and neighbourhoods in order to better graspempirically and theoretically - this relation. Building on these various aspects, and after briefly discussing the data collection, the fourth section examines empirically the formation of personal networks and the role of the neighbourhood. The final section offers some recommendations for future research and neighbourhood mixing policies.

\section{Network poverty and the role of the (poor) neighbourhood}

\subsection{Sociospatial isolation and networks}

Living in a poor neighbourhood may have various negative impacts on people's everyday lives and their position in society. One possible negative impact is that they might suffer 
from network poverty, ${ }^{1}$ more than people who live in socioeconomically mixed or affluent neighbourhoods (see e.g. Ellen and Turner 1997; Kintrea and Atkinson 2001). Network poverty refers to having a personal network including merely or mostly resource-poor people and, thus, lacking ties to resources such as knowledge, wealth, skills, power and information. Embeddedness in resource-rich networks provides people with access to resources that they do not have themselves and through accessing these resources people may be able to create opportunities to improve their socioeconomic position (cf. the definition of social capital, see Bourdieu 1986). The question now is whether living in a poor neighbourhood negatively affects the formation and resourcefulness of people's networks. In the American literature, this is sometimes posed as a problem of "social isolation". The original meaning of social isolation was that of personal isolation: a lack of relationships as such (Klinenberg 2002). Since Wilson's (1987, 1996) thesis of social isolation, as part of his work on poverty concentration effects, it has come to mean rather isolation from resource-rich others (Klinenberg 2002). According to this idea, poor people living in poor neighbourhoods are segregated not only along lines of socioeconomic status (and ethnicity/race) but also along lines of place (Wacquant 2008). The consequences are that poor people living in poor neighbourhoods have fewer opportunities to meet and socialize with resource-rich people: the latter are simply not present as neighbours or as fellow-residents engaging in neighbourhood institutions. Considering that personal networks are one way to gain access to valuable resources, spatial segregation thus negatively affects people's opportunities to gain resources and thus to improve their socioeconomic position. Socially isolated people lack relationships that might offer opportunities for "social leverage" (Briggs 1998). More generally, spatial segregation would then reproduce the uneven distribution of resources, thus reproducing inequality.

In order to understand whether and how poverty concentration produces network poverty, we need to examine how the neighbourhood plays a role in network formation. Networks of poor people are on average less geographically dispersed (see Wellman 1979; Fischer 1982; Blokland 2003; Mulder and Kalmijn 2004; van Eijk 2010). This suggests that a greater proportion of their network is formed or maintained in the neighbourhood, whereas the networks of resource-richer people are largely formed and maintained outside the neighbourhood. We would thus expect that neighbourhoods have a more significant role in the formation of the geographically concentrated networks of poor people. However, this is not as self-evident as it may seem. First, the question remains whether and to which extent personal networks are actually formed in the neighbourhood. Second, we need to know how the neighbourhood plays a role in network formation, in order to understand the (possible) causal relationship. I briefly elaborate these questions now.

\subsection{Local networks and locality-based relationships}

First, we need to know whether people's networks include many or few network members who live in their neighbourhood. The everyday lives of people might take place predominantly or exclusively in their neighbourhood due to, for example, limited financial means or limited social, economic or political participation. When people participate in few other settings, for instance because they have no job, because they lack membership of social or political associations, or because they spend most of their leisure time in and around the house, their possibilities to form relationships with others in such settings

\footnotetext{
1 The term 'network poverty' is borrowed from Perri 6 (1997)
} 
is obviously limited. A second question is whether these people "compensate" for this through forming more relationships with fellow-residents. Wellman (1999: p. 4), for example, argues that nowadays usually only a 'less-mobile minority'—children, stay-athome moms, the elderly and the infirm-have relationships with their neighbours 'because they must'. This implies that if people had alternatives through engagement in nonneighbourhood settings, they would not have (as much) neighbour relationships. In a similar vein, Völker and Flap (2007: p. 263) argue that 'if one has no other members in their personal network, neighbours become the first (and only) choice.' However, Wellman as well as Völker and Flap focus on neighbours and this leaves open the question as to what extent people form other kinds of relationships with fellow-residents, for example friendships or acquaintanceships. Neighbours are merely one category of local ties, next to other fellow-residents and those fellow-residents who have become friends, colleagues or club members. When we think about local networks, we should thus not think only of "neighbours".

We can now rephrase the question of how neighbourhoods matter for networks. Resource-poor people appear to have geographically concentrated networks, but the question is whether this is due to a lack of relationships formed and maintained outside the neighbourhood, or rather to the fact that they form and maintain a greater number of relationships with fellow-residents. In the first situation, the neighbourhood does not necessarily have to play a significant role in the (bounded) formation of their networks. In the latter situation, however, the importance of the neighbourhood in network formation increases, because people draw new network members from the neighbourhood population. Consequently, the composition of the neighbourhood matters more in the latter case.

A next step is to distinguish local relationships from locality-based relationships. Local relationships are those relationships with people living in the same neighbourhood and may include next-door neighbours, family members, friends, colleagues, acquaintances, friends-of-friends and club members. These relationships need not be formed in the neighbourhood. Relationships with family members are an obvious example: family ties usually develop through blood, marriage or adoption. Whether or how these ties are maintained may be contingent on geographical proximity and the use of neighbourhood settings. Relationships with friends and colleagues may have been formed in other, nonneighbourhood settings and (at a later point) maintained in the neighbourhood. Relationships with next-door neighbours are often formed as well as maintained in the neighbourhood-these relationships are not only local but also locality-based. The same goes for relationships with fellow-residents that are formed through neighbourhood meetings, activities at the community centre or through repeated encounters at the children's playground or local café. Note that these locality-based relationships can transform into friendships, family members (through marriage) and colleagues. The labels that are often used to describe relationships- "friends", "acquaintances", "neighbours", "colleagues" - thus say little about the origin of the relationships (cf. Blokland 2003). Locality-based relationships thus refer to relationships with fellow-residents that are formed in the neighbourhood or in neighbourhood settings. Locally maintained relationships, on the other hand, refer to relationships with people who live in the same neighbourhood but which were not initially formed in the neighbourhood. Together, these types of relationships form people's "local network". Below I empirically examine these elements of networks and the neighbourhood, in order to grasp the significance of poor neighbourhoods for network poverty. First, I briefly describe the data collection and the question of generalization. 


\section{Data and methodology}

This paper is based on in-depth interviews with 15 people living in a poor neighbourhood (Hillesluis) and 15 people living in an affluent neighbourhood (Blijdorp) in Rotterdam. Measured by the share of people with an income below the poverty line and those with a high income, Hillesluis is a relatively poor area and Blijdorp a relatively affluent area (see Table 1). Just over half of the Hillesluisians have income from work, compared to three quarters of the Blijdorpers. Nearly $30 \%$ of the Hillesluis population and 5\% of the Blijdorp population receive unemployment or disability benefits. The differences in socioeconomic status reflect in the ethnoracial composition of the population. In Hillesluis, people of Turkish, Surinamese and Moroccan origin dominate the category of non-Western minorities (together 56\%). In Blijdorp, the category of non-Dutch residents includes more residents of Western origin. The presence of people of non-Western origin in Hillesluis shows through the many ethnic shops and restaurants and several religious establishments. Hillesluis is according to national and local policy-makers a "problem neighbourhood" and is currently being transformed through urban renewal policies and housing differentiation. Blijdorp is a quiet area located near the city centre, with hardly any cultural facilities, cafés or bars and few shops. Young singles and young families find the neighbourhood very attractive and they are rapidly replacing the original, now elderly population. Young families however, also move out quickly because most apartments are relatively small. Hillesluis houses relatively more households with children, among which more single parents. Finally, the population reflects differences in the housing stock: in Hillesluis, more than half of the stock is owned by housing associations, compared to $3 \%$ in Blijdorp. In both neighbourhoods, the housing stock consists mostly of low-rise flats and apartment buildings.

Table 1 Sociodemographic characteristics of the populations and characteristics of the housing stock of the two research neighbourhoods (percentages)
Income below poverty line is an officially used indicator of Statistics Netherlands based on the consumer purchasing power corrected for household composition, and lies just above supplementary benefit level.

Ethnic origin is based on official classification, i.e. when someone and his/her both parents were born in the Netherlands, one is classified as Dutch. Statistics are for 2005 (socioeconomic status) and 2007 (other statistics).

Source: BIRD, 2010

\begin{tabular}{lll}
\hline & Hillesluis & Blijdorp \\
\hline Socioeconomic status & & \\
Income below poverty line & 26 & 8 \\
High income (top 20\%) & 6 & 28 \\
Social security dependents & 29 & 5 \\
Ethnic origin & & \\
Non-Western & 74 & 10 \\
Western, non-Dutch & 6 & 13 \\
Dutch & 20 & 77 \\
Household composition & & \\
Couple with children & 27 & 12 \\
Single parent & 14 & 6 \\
Couple/single no children & 58 & 80 \\
Housing stock & & \\
Social rental & 60 & 3 \\
Private rental & 17 & 55 \\
Owner-occupied & 22 & 42 \\
Single-family dwelling & 6 & 2 \\
Apartments/flats & 94,197 & 989 \\
Number of residents in research area & & \\
\hline & &
\end{tabular}


The interviews followed up on a survey on personal networks and support (see van Eijk 2010). Of those respondents who gave permission to us to approach them for a second interview, I selected respondents for their theoretical relevance (Babbie 2001: p. 193): people with a (large) resource-rich network and people with a small or resource-poorer network. In this way, I would be able to identify how differences in networks had developed. In 2009, I interviewed 12 men and 18 women, of whom 11 in their thirties, 4 in their forties, 9 in their fifties and six aged 60 and older. Most are of them are of native Dutch origin (18); of the non-Dutch, nine are of non-Western origin. Thirteen respondents have limited or low education: primary and secondary school and low-level vocational training; seventeen respondents have high education, which refers to medium-and highlevel vocational training, and academic education.

The in-depth interviews were based on a topic list and addressed, among other things, the origin and development of relationships with network members. All interviews were recorded, transcribed, coded and analysed with the help of qualitative data analysis software ATLAS.ti. The names of the respondents mentioned in this paper are fictitious.

Some words about the generalization of the study findings are warranted. The data do not allow for empirical generalization, although the findings might hold for similar people who live in similar types of (Dutch) urban neighbourhoods. My aim is, however, to make a theoretical argument regarding the role of the neighbourhood in the formation of personal networks and to identify the various elements that may mediate whether neighbourhood composition matters for people's networks. Other studies may find similar patterns and tendencies although the empirical details may be different (moderatum generalization, Payne and Williams 2005). I use my data to show how the neighbourhood matters for network formation and thus aim to demonstrate the validity of my theoretical argument.

\section{The role of the neighbourhood in network formation}

I now zoom in on the formation of personal networks of Hillesluisians and Blijdorpers. In Sect. 2, I argued that, firstly, in order to understand whether and how the neighbourhood and its composition matter, we need to know the extent to which personal networks are formed and maintained in the neighbourhood; secondly, we need to distinguish locally maintained relationships from locality-based relationships; and thirdly, we need to consider how the neighbourhood plays a role in the formation of relationships between fellowresidents.

\subsection{Network localness}

The proportion of local ties in the network-network localness-is an indicator for whether and to what extent people form relationships with fellow-residents. Table 2 offers some descriptive statistics on the location of respondents' personal networks. ${ }^{2}$ It shows total network size, the number and proportion of local and non-local ties, and the number and proportion of "trusted neighbours". The latter measure refers to a question specifically about local ties. Respondents were asked: "Is there a neighbour you particularly trust?" I included this measure to see whether people with small networks are inclined to form more relationships with fellow-residents. Note, however, that these "trusted neighbours"

\footnotetext{
${ }^{2}$ Note that the number of respondents is not sufficient for statistical analyses; the statistics serve descriptive purposes only.
} 
Table 2 Characteristics of respondents' personal networks, by level of education

Low educational

level $=$ primary/secondary school and low vocational training; high educational level $=$ medium $/$ high vocational training and academic education

\begin{tabular}{llll}
\hline & All & \multicolumn{2}{l}{ Level of education } \\
\cline { 3 - 4 } & & Low & High \\
\hline $\begin{array}{l}\text { Number of network members } \\
\text { Network localness in proportions }\end{array}$ & 8.50 & 7.09 & 9.59 \\
$\begin{array}{l}\text { \% Local ties (not trusted neighbours) } \\
\text { in network }\end{array}$ & 32 & 41 & 25 \\
$\begin{array}{l}\text { \% Trusted neighbours in network } \\
\text { \% Non-local ties in network }\end{array}$ & 18 & 22 & 15 \\
Network localness in numbers & 50 & 36 & 61 \\
$\begin{array}{l}\text { Number of local network members } \\
\text { Number of trusted neighbours }\end{array}$ & 2.60 & 2.85 & 2.41 \\
$\begin{array}{l}\text { Number of non-local network } \\
\text { members }\end{array}$ & 1.57 & 1.62 & 1.53 \\
N & 4.33 & 2.62 & 5.65 \\
\hline
\end{tabular}

may also be family members or friends living in the neighbourhood. The local and nonlocal networks say nothing about the type of connection (family members, friends, colleagues, neighbours, etcetera); they merely indicate the place of residence of network members. Household members (partners, children living at home) are excluded from the local network.

The networks on average include eight to nine network members and are larger for people with higher-level education. Other studies have shown that network size and network localness (i.e. the share of network members that live in the same neighbourhood) is associated with socioeconomic status (Fischer 1982; Mulder and Kalmijn 2004; van Eijk 2010). I take educational level as an indicator of the respondent's socioeconomic status. In line with other studies, resource-poor respondents have more geographically concentrated networks than resource-richer respondents: a greater proportion of their ties live in the same neighbourhood. The share of local ties and neighbours in the network is also higher for people with low-level education. Resource-poorer people thus are more likely to have a locally-based network, which suggests that the composition of the neighbourhood would affect their networks more than the networks of affluent people. Still $36 \%$ of resource-poor respondents' networks are non-local ties, indicating that they do not solely rely on local ties.

However, when we look at the number of local ties and neighbours, we find that this quite similar for both respondent categories. It is particularly the number of non-local network members that differs: people with higher-level education reported more than twice as many network members who live outside their neighbourhood. This suggests that people with (relatively) small networks do not necessarily compensate for this by forming more relationships with people living in their neighbourhood. In other words, that network localness is higher for people of lower socioeconomic status does not mean that their neighbourhood plays a greater role in network formation. This is important for understanding whether the neighbourhood reproduces network poverty. The significant difference in the number of non-local relationships suggests that the engagement in nonneighbourhood settings yields a more extensive - and perhaps a more resourceful-personal network. In the next section, I address these patterns through examining the formation of networks in more detail. 


\subsection{Locally maintained and locality-based relationships}

The extent to which people either locally maintain relationships that originated in other settings or form new relationships with fellow-residents matters for whether the neighbourhood composition might have impact on the composition and resourcefulness of their personal networks. Only in the latter case do people draw new network members from the neighbourhood population. This raises the question as to whether the localness of networks is an accurate indicator for understanding how resource-poor networks develop. I already suggested that people with small networks do not necessarily form more relationships with fellow-residents. The data further shows that it is rather the extent to which networks are bounded to few (i.e. one or two) settings that is important for understanding network poverty. The difference between the networks of resource-poor and resource-rich people is that the latter extend their network through their engagement with others in settings such as those related to study, work, leisure and political participation.

In Hillesluis (poor neighbourhood), I talked with Rosita (b.1959), a single woman with two adult daughters and at the time of the interview unable to work (she had worked previously in cleaning and administrative jobs). Her personal network includes mainly family members: brothers, sisters and daughters, some of whom live abroad in the country were she was born, and her aunt. She is not close with all family members to the same extent; she socializes particularly with the family members living in Rotterdam and surroundings. None of her family members lived in her neighbourhood. Her "best friend" lives a couple of doors down from her. She had not met her friend in her street but through her sister; the relationship between her sister and her friend went back to secondary school and it was merely a coincidence that Rosita and her friend became neighbours. Sometimes Rosita would meet new people via her sister and her friend, who, she explained, are more outgoing than she is. Her family thus seems to be the core setting in which she expands her network. Her neighbourhood does seem to facilitate the development of a close relationship with her friend, particularly because Rosita is limited in travelling far due to health problems. Certain settings in the neighbourhood such as the shopping street play a role in maintaining their friendship.

In Blijdorp (affluent neighbourhood), I talked with Bernadette (b.1957; co-habiting, one grown-up son). Before she suffered from health problems, Bernadette worked in middle management. She had lost most of her study friends; she believes that they were not willing to be patient with her recovery. Bernadette's network includes family members (the nuclear family and a niece living abroad, with whom she recently re-established contact) and two friends. These are friends she had met more recently in her neighbourhood. One of them, her "buddy", she met through walking the dogs: they repeatedly ran into each other, started talking and talked some more, and eventually started visiting each other. The other friend she had also met in Blijdorp, just through repeatedly seeing each other here and there. The networks of Bernadette and Rosita are examples of how limited participation in settings such as work, leisure and associations leaves the family and the neighbourhood as settings in which to meet new people and form relationships. While Bernadette seems to "compensate" for the loss of old friends by forming new friends in the neighbourhood, Rosita does not. For Rosita, the neighbourhood thus plays no role in the formation of her network and it would be difficult to see how the neighbourhood's composition would be "causing" network poverty.

Several respondents have a family-based personal network and maintain (some of) their relationships with family members in the neighbourhood. When people have little money to spend, geographical proximity may become more important for maintaining 
relationships. Another reason that may play a role in the formation of local family networks is that lower-educated people may feel less need or desire to move to other cities for their job (Mulder and Kalmijn 2004). Most resource-richer people also maintain ties with family members, but these would usually live farther away and they would make up a smaller proportion (but not necessarily a smaller number!) of individuals in the personal network. The family seems for the latter one of the many setting in which they form and maintain relationships and their network shows a greater variety of connections (besides family members also colleagues, college friends, club associates, and so on). This suggests that when people get involved in other settings than the family and the neighbourhood, new relationships are added to the personal network.

For some people, their neighbourhood plays a role in the formation of as well as the maintenance of their personal network. Murat (b.1973) is married and father of a toddler, and works for the local tax authorities. He lives in Hillesluis and has lived there most of his life. Some of his childhood friends and family members also still live there. Because Murat and (some of) his network members stayed in the neighbourhood it has been easy to remain in touch with friends and friends-of-friends with whom he played football in the streets when he was young. One of these local network members - a friend of his brother-told him about the vacancy that got him his current job. Through the job, Murat met other people and expanded his network.

Another respondent who has a local family-based network is Hafida (b.1973), married, mother of three young children and working as a nurse in the city hospital. Several of her (in-law) family members live in Hillesluis. She maintains no relationships with any of her direct neighbours. Through her study and job placement, she met new people and one of them told her about a job opportunity. For Hafida, as for Murat, the neighbourhood is a place for maintaining long-standing relationships rather than forming new ones. Her involvement in work-and study-related settings yielded a more extensive and resourceful network.

Several resource-rich Blijdorpers had been to university, got a job and started a family. Contacts with parents and siblings usually are maintained, but family members were relatively less prominent or lived in another city or region. Childhood friends had been replaced by fellow-students and later complemented with professional relationships. One of these resource-rich Blijdorpers is Liesbeth (b.1973), married with one toddler and selfemployed as communication coach. She has several girlfriends whom she met through study-related activities. A recent, new friend she met through a professional network. She has established a "friendship" with one of her neighbours who also has young children. Here we have an example of how not only resource-poor people draw new relationships from a neighbourhood setting: resource-rich people are equally likely to do so. Nevertheless, as part of Liesbeth's broader network, locality-based relationships make up a smaller proportion of the network. This means that the resourcefulness of her personal network is contingent more on settings related to study and work than on her (affluent) neighbourhood.

The same goes for Carlo (b.1971), working in information management at a welfare company, who had re-joined with his present wife at the local supermarket in Blijdorp. They now live together and have a young daughter. Every now and then he bumps into a former colleague, with whom he maintains "warm relations" and whom he would call up if he were to consider a career shift. Carlo and his wife formed several friend-like relationships with their fellow-residents who live in their street and who all have children of more or less the same age. Carlo goes jogging every week with one neighbour, shares a motor caravan with others, exchanges children's clothes with still others, and on birthdays 
and New Year's Eves they seek out each other. His local neighbour network exists next to an extensive network of friends, (former) colleagues, acquaintances and his parents.

The detailed information on the origin of relationships and the formation and maintenance of personal networks suggests that high network localness does not mean that people are "locally-oriented" in forming new relationships. Resource-poor people may rather maintain relationships through geographical proximity. Local ties are not necessarily formed in the neighbourhood. When it comes to the role of the neighbourhood in network formation, the main difference is that for resource-rich people, the neighbourhood is one of the many contexts in which they form new ties (besides family relations), while for resource-poor people it is one of few or the only context in which they form new ties. This suggests that resource-poor networks result in the first place from a lack of participation in other settings and consequently the neighbourhood's role is more prominent. Network poverty, however, has more to do with the (limited) number of contexts in which people engage than with spatial isolation. This thus does not confirm the role of the neighbourhood in causing or perpetuating poverty.

\subsection{Neighbourhood settings}

Finally, we may ask how, if at all, the neighbourhood plays a role in the formation of relationships. The "neighbourhood" as setting in which relationships develop is too broad to do any meaningful analytical work. The in-depth interviews show that relationships form in "neighbourhood settings" such as a residents' association, a community centre, a school, a playground or park, and the "micro-neighbourhood". Residents are able to form relationships with fellow-residents through settings when these are neighbourhood settings: when they attract mainly and mostly people from the neighbourhood population (cf. Small 2009). The "micro-neighbourhood" refers to adjacent and opposite dwellings such as a subsection of street and street blocks and-typical for Dutch urban neighbourhoodswalk-up flats (cf. the micro-setting in Kusenbach 2008). Within this setting, familiar routines develop and proactive intervention—support and vigilance-between neighbours occurs (rather than reactive actions). In so far that personal relationships and intimate relationships between fellow-residents develop, it usually happens within the microneighbourhood (ibid.). Other geographies of the neighbourhood-street blocks, walking distance neighbourhoods, and enclaves - are not without meaning but rather for other forms of "community" such as enacting feelings of responsibility, for instance through collective action, and the creation of a shared identity or benefiting from supplies for particular lifestyles (ibid.).

Relationships with "neighbours" (note that this is a sub-category of fellow-residents) usually had formed in the micro-neighbourhood and often materialized in greetings and small talk, exchange of keys and small favours such as watching one's pets or plants during holidays. Several respondents had also developed more intimate and more frequent ties with people living next-door or across the street. The micro-neighbourhood for them serves to expand the personal (support) network. Umaima (b.1960), a single mother of two teenagers, unemployed and studying to do administrative work, has been living in Hillesluis for about 30 years. In 1993, she moved into the walk-up flat where she currently lives, simultaneously with her neighbour and they soon became friends. They both have young children and although they sometimes disagree about curfews and other parenting matters, they are "like sisters": they can laugh and cry together. Recently they had taken up sports lessons in one of the community centres, thus using other neighbourhood settings to maintain their locality-based relationship. 
Carlo, whom I have described briefly above, formed the only locality-based relationships he has in two overlapping settings: his micro-neighbourhood (a subsection of his street) and his daughter's (local) school. The school as neighbourhood setting thus facilitates the maintenance and development of locality-based ties.

Neighbourhood settings may particularly draw together people who are more or less purposively involved in such setting: parents involved in the community school, concerned residents attending the residents' association, residents depending on inexpensive services and activities visiting the community centre and people with dogs and children using, respectively, parks and playgrounds.

Bernadette's friendship with another dog-owner is one example. Here are some other examples. Riet (b.1946), a retired married woman who lives next-door to her son and grandchildren in Hillesluis, encounters many familiar fellow-residents on the streets whom she met when she did voluntary work at the community centre. Cor (b.1928) met fellowresidents through his activities for the residents' association in his building complex. Before he moved in, a committee was established and he has been involved ever since, thus expanding his network beyond his immediate neighbours.

Wibbe's (b.1960) personal network also demonstrates how neighbourhood settings get people in touch. One of his good friends he met in his micro-neighbourhood in Hillesluis. They live across the street from each other and their relationship had grown closer through their involvement in organizing children's activities. This organization provided a setting through which Wibbe got to know more fellow-residents. It was through this setting that he met a community worker who involved him in other neighbourhood activities and provided Wibbe with an opportunity to influence decisions about his neighbourhood. Sometimes engagement in one setting draws people into other settings through which they get to meet more people and become involved in more and different social circles.

While people may not have planned to form new relationships, gatherings of a particular public allow a specific setting to facilitate the formation of relationships (cf. Curley 2009: pp. 94-95; Small 2009). Small (2009) for instance describes how child care centres in New York City become settings through which relationships between parents (mostly mothers) can develop. He observes that while many of these relationships remain "compartmental" they are maintained exclusively within the setting in which they were initially formed-they nevertheless can be valuable for the exchange of resources such as information.

Neighbourhood settings function not only as places where people meet others but also as places where people socialize with each other; in other words, where they maintain their relationship. Jannie (b.1950), for example, had met her "best friend" in her microneighbourhood in Blijdorp - they live across the street from each other-and their relationship had developed through their children who are childhood friends. They used to take their daughters to school together and now that their daughters had grown up, Jannie and her friend maintained contact through a weekly hobby club in their neighbourhood. The micro-neighbourhood, however, formed the most important setting for maintaining contact. Jannie realized this after she had moved to a dwelling a few streets farther away (she moved in between the first and second interview) and she regretted that she couldn't just "pop in" at her best friend's place.

Rarely ever did respondents develop relationships from mere chance encounters. In the neighbourhood, encounters are structured through neighbourhood settings. Most encounters may not develop into personal relationships, but repeatedly being in the same place at the same time provides possibilities for people to develop relationships. Neighbourhood settings are thus 'foci of activity' (Feld 1981: p. 1019; Feld and Carter 1998): 'persons, places, social positions, activities and groups' which 'actively bring people together or 
passively constrain them to interact.' Without these foci, people would probably not meet fellow-residents who do not live in their micro-neighbourhood, simply because the likelihood of repeated encounters decreases without settings that are part of daily routines and leisure activities.

\section{Conclusion}

In this paper, I have scrutinized how the socioeconomic composition of neighbourhoods might shape personal networks and whether living in a poor neighbourhood can cause network poverty. Policy-makers concerned with poverty concentration neighbourhoods worry that the neighbourhood composition reflects in the resourcefulness of people's networks. In this paper, I have teased out how the neighbourhood in which people live matters for how their network develops. My conclusion is threefold. First, high network localness does not necessarily mean that people draw new network members from the neighbourhood population; they may rather locally maintain relationships that originated in other settings (e.g. family ties or school friends). Second, resource-poor people with small networks do not seem to compensate for their small network by forming more ties with fellow-residents. The difference in network formation between resource-poor and resourcerich people is rather that the latter draw network members from a wider variety of settings, such as work, study, leisure and associations. "Social isolation" thus seems to be not a spatial problem but a problem of differential (opportunities for) participation in certain settings. Particularly study and work yield resourceful relationships. Third, as far as relationships are formed within the neighbourhood, these form in "neighbourhood settings" and thus it is the composition of these settings that may reflect in people's networks rather than the composition of an entire neighbourhood (although these two populations may be more or less associated).

What does this mean for the way we think about poverty concentration, its effects on networks and social mixing policies? With regard to future research, studies on (poverty) networks need more refined measures of, in particular, the localness of networks and the extent to which networks were formed in the neighbourhood. By not including a measure of (the proportion of) locality-based ties, studies run the risk of overestimating "neighbourhood effects" on networks. That is, variations in network resourcefulness among neighbourhood populations may reflect the different ways in which people of different socioeconomic statuses form and maintain their networks differently. Research thus needs more fine-tuning to draw this out.

With regard to urban policies, the focus needs to shift from neighbourhood composition to neighbourhood setting. Urban policies in the Netherlands as well as other Western countries promote housing differentiation and state-led gentrification in order to create socioeconomically mixed neighbourhoods (see Kleinhans 2004; Andersson et al. 2007; Lees 2008; van Kempen and Bolt 2009; Arthurson 2010). These policies seem to be informed by (academic) concerns about the alleged negative effects of poverty concentration. However, mechanisms of network formation and variations in neighbourhood use and geographical mobility of people seem to get lost in the broad strategies of social mixing. As I have shown in this paper, these aspects are crucial for understanding whether, how and for whom negative effects of living in concentrated poverty may arise. Living in a poor neighbourhood in Dutch cities might be associated with but not a cause of network poverty. For those people with small networks who do not compensate by forming many relationships with fellowresidents, it is difficult to see how the neighbourhood would have an impact on their 
networks. Furthermore, even if people depend solely or mainly on poor fellow-residents, we may ask whether this is a neighbourhood problem or whether the problem lies in limited opportunities to meet and engage with people in non-neighbourhood settings.

Furthermore, the neighbourhood as a collection of hundreds or thousands of people has little meaning for network formation. Within these large geographical areas, settings attract particular segments of the neighbourhood population and it is in these settings that people meet and maintain relationships. If we seek to identify sites that have a meaningful role in bringing together members of a neighbourhood population, we need to focus on those sites that attract residents. Whether settings attract mainly residents varies with the location and function of neighbourhoods - for example, whether it is a residential area or part of the entertainment or business district. We can thus understand "the neighbourhood" as a collection of neighbourhood settings. Such settings may mediate potential effects of the neighbourhood composition when they draw particular segments of the neighbourhood population (Small 2004). It is through people's engagement with these settings that their networks may or may not reflect the neighbourhood population. This also means that a more mixed population is unlikely to influence the composition of personal networks when neighbourhood settings are homogeneous because of segregated engagement in these settings. Neighbourhood settings thus need to attract a variety of socioeconomic categories in order to facilitate the formation of relationships between resource-poor and resourcerich residents. Such strategies as housing differentiation should thus be accompanied by initiatives that get together people from different socioeconomic categories. Because relationships between different socioeconomic categories are difficult to stimulate, these initiatives may be more successful when they focus on transforming ephemeral encounters into repeated encounters (RMO 2005: p. 45). Such settings need to be multifunctional to attract a diverse public; visiting these settings should be part of people's everyday routines and should thus not take too much additional effort; and these settings should offer longterm perspective support, for example for toddlers and adolescents (ibid.: pp. 46-47). Because spatial segregation is interwoven with segregation in multiple domains of life, social mixing policies can only be successful if they are accompanied by additional initiatives to facilitate the formation of mixed networks.

Acknowledgments The research for this paper was carried out while I was working at the OTB Research Institute for Housing, Urban and Mobility Studies, Delft University of Technology. Thanks are due to the editors of this special issue for their comments on an earlier draft of the paper.

Open Access This article is distributed under the terms of the Creative Commons Attribution Noncommercial License which permits any noncommercial use, distribution, and reproduction in any medium, provided the original author(s) and source are credited.

\section{References}

Andersson, R., Musterd, S., Galster, G., \& Kauppinen, T. M. (2007). What mix matters? Exploring the relationships between individuals' incomes and different measures of their neighbourhood context. Housing Studies, 22, 637-660.

Arthurson, K. (2010). Operationalising social mix: Spatial scale, lifestyle and stigma as mediating points in resident interaction. Urban Policy and Research, 28, 49-63.

Babbie, E. (2001). The practise of social research. Belmont: Wadsworth.

Blokland, T. (2003). Urban bonds. Social relationships in an inner city neighbourhood. Cambridge, UK: Polity Press. 
Bourdieu, P. (1986). The forms of capital. In J. G. Richardson (Ed.), Handbook of theory and research for the sociology of education (pp. 241-258). New York: Greenwood Press.

Briggs, X. d. S. (1998). Brown kids in white suburbs: Housing mobility and the many faces of social capital. Housing Policy Debate, 9, 177-221.

Curley, A. M. (2009). Relocating the poor: Social capital and neighbourhood resources. Journal of Urban Affairs, 32, 79-103.

Ellen, I. G., \& Turner, M. A. (1997). Does neighborhood matter? Assessing recent evidence. Housing Policy Debate, 8, 833-866.

Feld, S. L. (1981). The focused organization of social ties. American Journal of Sociology, 86, 1015-1035.

Feld, S., \& Carter, W. C. (1998). Foci of activity as changing contexts for friendship. In R. G. Adams \& G. Allan (Eds.), Placing friendship in context (pp. 136-152). Cambridge: Cambridge University Press.

Fischer, C. S. (1982). To dwell among friends. Personal networks in towns and city. Chicago: University of Chicago Press.

Galster, G. (2001). On the nature of neighbourhood. Urban Studies, 38, 2111-2124.

Gans, H. J. (2008). Involuntary segregation and the ghetto: Disconnecting process and place. City \& Community, 7, 353-357.

Kearns, A., \& Parkinson, M. (2001). The significance of neighbourhood. Urban Studies, 38, 2103-2110.

Kintrea, K., \& Atkinson, R. (2001). Neighbourhoods and social exclusion: The research and policy implications of neighbourhood effects. Glasgow: University of Glasgow, Urban Change and Policy Research Group.

Kleinhans, R. (2004). Social implications of housing diversification in urban renewal: A review of recent literature. Journal of Housing and the Built Environment, 19, 367-389.

Klinenberg, E. (2002). Alone in the city? An intellectual history of social isolation, Working Paper-02-15. (Northwestern University: Institute for Policy Research Working Paper).

Kusenbach, M. (2008). A hierarchy of urban communities: Observations on the nested character of place. City \& Community, 7, 225-249.

Lees, L. (2008). Gentrification and social mixing: Towards an inclusive urban renaissance? Urban Studies, 45, 2449-2470.

Mulder, C., \& Kalmijn, M. (2004). Even bij oma langs. Demos, 20, 78-80.

Payne, G., \& Williams, M. (2005). Generalization in qualitative research. Sociology, 39, $295-314$.

Perri, 6. (1997). Social exclusion: Time to be optimistic. Demos Collection, 12, 1-24.

Pinkster, F. M. (2008). Living in concentrated poverty [PhD thesis]. (Amsterdam: University of Amsterdam).

RMO (2005). Niet langer met de ruggen naar elkaar. Een advies over verbinden. Den Haag: Raad voor Maatschappelijke Ontwikkeling.

Sampson, R. J., Morenoff, J. D., \& Gannon-Rowley, T. (2002). Assessing "neighborhood effects": Social processes and new directions in research. Annual Review of Sociology, 28, 443-478.

Small, M. L. (2004). Villa Victoria: The transformation of social capital in a Boston barrio. Chicago: University of Chicago Press.

Small, M. L. (2007). Racial differences in networks: Do neighborhood conditions matter? Social Science Quarterly, 88, 320-343.

Small, M. L. (2009). Unanticipated gains. Origins of network inequality in everyday life. New York: Oxford University Press.

van Eijk, G. (2010). Unequal networks. Spatial segregation, relationships and inequality in the city [PhD thesis]. (Amsterdam: IOS Press).

van Kempen, R., \& Bolt, G. (2009). Social cohesion, social mix, and urban policies in the Netherlands. Journal of Housing and the Built Environment, 24, 457-475.

Völker, B., \& Flap, H. (2007). Sixteen million neighbors: A multilevel study of the role of neighbors in the personal networks of the dutch. Urban Affairs Review, 43, 256-284.

Wacquant, L. (2008). Urban outcasts. Towards a sociology of advanced marginality. Cambridge: Polity.

Wellman, B. (1979). The community question: The intimate networks of East Yorkers. American Journal of Sociology, 84, 1201-1231.

Wellman, B. (1999). From little boxes to loosely-bounded networks: The privatization and domestication of community. In J. Abu-Lughod (Ed.), Sociology for the twenty-first century: Continuities and cutting edges (pp. 94-114). Chicago: University of Chicago Press.

Wilson, W. J. (1987). The truly disadvantaged: The inner city, the underclass, and public policy. Chicago: University of Chicago Press.

Wilson, W. J. (1996). When work disappears. The world of the new urban poor. New York: Vintage books. 